(2) Open Access Full Text Article

SHORT REPORT

\title{
Assessing the safety and quality of ward-based renal transplant biopsies
}

This article was published in the following Dove Press journal:

Transplant Research and Risk Management

5 October 2010

Number of times this article has been viewed

\author{
Kenneth $\mathrm{Wu}^{\prime}$ \\ Bindhu Musunuru' \\ Chera Arunachalam' \\ Aung Sett ${ }^{1}$ \\ Paul Musker ${ }^{2}$ \\ 'Renal Unit, St James' University \\ Hospital, Leeds, West Yorkshire, \\ UK; ${ }^{2}$ Renal Unit, St Luke's Hospital, \\ Bradford, West Yorkshire, UK
}

Correspondence: Paul Musker

Lakes District Health Board, Emergency

Department, Rotorua Hospital, Private

Bag 3023, Rotorua Mail Centre, Rotorua

3046, New Zealand

Tel +64 7348 II 99

Fax +6473497952

Email sabrebadger@hotmail.com

\begin{abstract}
The aim of this pilot study was to compare renal transplant biopsies carried out by ward-based nephrology trainees and departmental based radiologists, primarily reviewing major complications and glomerular yield. There was only one patient who developed a single episode of major complication out of the 145 procedures recorded. We concluded there is no significant difference in complication rate and glomerular yield for renal allograft biopsies between nephrology trainees and radiologists, regardless of location.
\end{abstract}

Keywords: renal transplant, kidney biopsy complications, renal hemorrhage, glomerular yield

\section{Introduction}

Renal biopsy is a well established investigation, providing important information regarding diagnosis and prognosis of many medical conditions. Like liver biopsy, this procedure can be performed by physicians, surgeons and radiologists as the skill can be acquired with time and practice. ${ }^{1}$

Dysfunctional renal alleografts after renal transplantation often require urgent histological assessment. As radiological resources are not unlimited, some transplant units have therefore elected to perform ward-based percutaneous biopsies by clinicians in order to obtain prompt diagnosis. To date, there has been no rigorous trial to compare the safety and adequacy of renal transplant biopsies between physicians on the ward and radiologists in the radiology department.

This study was carried out primarily to review the major complication rate needing intervention and glomerular yield between bedside renal transplant biopsies performed by nephrology trainees and departmental biopsies performed by radiologists. Minor complications such as self-limiting small perirenal hemorrhage, pain and hematuria are not discussed in this article.

\section{Method}

A retrospective review of 149 renal transplant allograft biopsies was carried out. Information was collected from a computer database and medical case notes between June 2004 and December 2006. All biopsies from June 2004 to February 2005 were carried out in the radiology department prior to the introduction of the portable ultrasound machine in the renal ward in 2005. Subsequently, nearly all renal transplant biopsies were performed by nephrology trainees. All biopsies were performed under real-time ultrasound guidance using an automated spring loaded device. The core biopsy needles 
Table I Comparison between bedside renal transplant biopsy by nephrology trainees and departmental biopsy by radiologists

\begin{tabular}{lllll}
\hline & Nephrologists & Radiologists & Total & P values \\
\hline Number of biopsies & 93 & 52 & 145 & NA \\
Number of hemorrhage & 1 & 0 & 1 & 1.00 \\
Number of specimens with $\geq 10$ glomeruli & 41 & 23 & 64 & 0.98 \\
Mean number of glomeruli per procedure & 10.7 & 11.8 & 11.3 & $\mathrm{NA}$ \\
Samples with medulla only & 3 & $\mathrm{I}$ & 4 & 0.63 \\
Insufficient renal tissue & 5 & $\mathrm{I}$ & 6 & 0.32 \\
Mean number of passes & 1.98 & 1.47 & $\mathrm{NA}$ \\
\hline
\end{tabular}

Abbreviation: NA, not applicable.

used by both groups were $18 \mathrm{G}(1.2 \mathrm{~mm} \times 160 \mathrm{~mm}$ gauge $)$. Adequacy of core tissue samples was judged according to number of glomeruli as defined by a revised Banff criteria ( $>10$ glomeruli). ${ }^{2}$ Two sided Fisher's exact test was chosen for statistical analysis.

\section{Results}

Four cases were excluded due to incomplete data. There were 93 and 52 biopsies carried out by nephrology trainees and radiologists respectively. The overall major complication rate was surprisingly low at $0.7 \%$. There was only one major complication out of all the cases reviewed. This was an episode of significant hemorrhage noted in the nephrology group. The patient developed perirenal hemorrhage and hydronephrosis due to ureteric blood clots, requiring nephrostomy and a blood transfusion before making an uneventful recovery. Despite this event, there was no statistical significance $(P$ value $=1.0)$ of complication rate between the two groups. The risk difference was 0.01 ( $95 \%$ confidence interval $[\mathrm{CI}]-0.02$ to 0.04$)$. Although adequacy of tissue samples in both groups is similar ( $44.1 \%$ versus $44.2 \%$ ), clinicians appeared to have a higher likelihood of obtaining insufficient renal tissues (5.38\% versus $1.92 \%)$. However, this again did not achieve any statistical significance $(P$ value $=0.32)$. There were no deaths or graft losses. Other details are summarized in Table 1. Table 2 shows that there was no increased risk of hemorrhage in patients with relatively high international normalized ratio (INR) (1.4-1.6) at the time of biopsies ( $P$ value 0.65$)$.

\section{Discussion}

There has been a study in recent years involving 37 patients reporting the complication rate between radiologists and

Table 2 A comparison between INR value and cases of hemorrhage

\begin{tabular}{lll}
\hline & INR I-I.3 & INR I.4-I.6 \\
\hline Total number of cases recorded & 109 & 22 \\
Number of cases with hemorrhage & I & 0 \\
\hline
\end{tabular}

Abbreviation: INR, international normalized ratio. nephrologists in native kidney biopsies. ${ }^{3}$ To our knowledge, this is the first study to analyze the safety and glomerular yield of renal transplant biopsies between nephrology trainees and radiologists. The low incidence of complication in comparison to other studies is possibly due to the use of $18 \mathrm{G}$ biopsy needles. ${ }^{4}$ Furthermore, renal allograft biopsy complication rate is generally lower than that of native biopsies.

This research has shown that there is no significant difference in major complication rate of renal allograft biopsies, whether these are performed by nephrology trainees on the ward or by radiologists in radiology departments. Furthermore, glomerular yield measurements are also comparable between the two groups thereby ensuring quality of the biopsies is consistent. The obvious limitations to this study include it being a single center study, and a retrospective review rather than a randomized controlled trial. Other confounders that should be taken into account include different rooms, operators and ultrasound machines used for each procedure.

In conclusion, we have not found any difference in risk between bedside and departmental biopsies. Hospitals should consider investing in portable ultrasound machines to facilitate physicians performing bedside biopsies. This would enable the prompt diagnosis and treatment for transplant recipients by increasing the number of clinicians who are able to perform this procedure. Apart from enabling clinicians to establish a prompt diagnosis, ward-based biopsy could also be time and cost-effective. It has been estimated that the cost of a hospital stay per patient per day in the United Kingdom ranges between $£ 200$ to $£ 1,000$ (depending on the type of ward and care required). It is not uncommon for patients to be deferred more than 24 hours in centers that lack expertise or dedicated biopsy sessions. For every 10 in-patients that are delayed by a day in undergoing the procedure could potentially incur an extra $£ 2,000$ to $£ 10,000$ pounds to the center. In addition to this, time efficiency (time saved from decision to the actual biopsy procedure) could be dramatically improved. Therefore, it seems logical to have the additional option of non-radiologists performing 
the procedure in the interests of time, cost and patient care. Similar studies on a larger scale involving multiple centers will be invaluable to further evaluate the outcome of native and transplant kidney biopsies in order to ensure patients are given timely optimal care and at the same time, not subjected to unnecessary risks.

\section{Disclosure}

The authors report no conflicts of interests relevant to this research.

\section{References}

1. Nicholson ML, Wheatley TJ, Doughman TM, et al. A prospective randomized trial of three different sizes of core-cutting needle for renal transplant biopsy. Kidney Int. 2000;58:390-395.

2. Racusen LC, Solez K, Colvin RB, et al. The Banff 97 working classification of renal allograft pathology. Kidney Int. 1999;55:713-723.

3. Gupta RK, Balogun RA. Native renal biopsies: Complications and glomerular yield between radiologists and nephrologists. J Nephrol. 2005;18:553-558.

4. Riehl J, Maigatter S, Kierdorf H, Schmitt H, Maurin N, Sieberth HG. Percutaneous renal biopsy: comparison of manual and automated puncture techniques with native and transplanted kidneys. Nephrol Dial Transplant. 1994;9:1568-1574.

\section{Publish your work in this journal}

Transplant Research and Risk Management is an international, peerreviewed open access journal focusing on all aspects of transplantation and risk management to achieve optimal outcomes in the recipient improving survival and quality of life. The journal welcomes submitted papers covering original research, basic science, clinical studies, reviews \& evaluations, guidelines, expert opinion and commentary, case reports and extended reports. The manuscript management system is completely online and includes a very quick and fair peer-review system, which is all easy to use. Visit http://www.dovepress.com/ testimonials.php to read real quotes from published authors.

Submit your manuscript here: http://www.dovepress.com/transplant-research-and-risk-management-journal 